\title{
Aspectos de sistemática e morfologia de Schizodon fasciatus Agassiz, 1829, Rhytiodus microlepis Kner, 1859 e Rhytiodus argenteofuscus Kner, 1829 (Osteichthyes, Characoidei, Anostomidae) do lago Janauacá - Amazonas (")
}

\author{
Geraldo Mendes dos Santos (**)
}

\section{Resumo}

São descritas variações do padrão de colorido nos diferentes estágios de desenvolvimento de Schizodon fasciatus, Rhytiodus microlepis e Rhytiodus argenteofuscus e analisados vários caracteres merísticos e morfológicos, visando uma melhor caracterizaçāo das espécies. Discutida a identificação da estranha pós larva de R. microlepis, já considerada como um gênero possivelmente novo de Anostomidae.

\section{INTRODUÇÃo}

A Bacia Amazônica possui a mais diversificada ictiofauna do mundo, abrangendo cerca de 1300 espécies descritas (Roberts, 1972) e, considerando-se que cerca de 30 a $40 \%$ da ic. tiofauna sul-americana de peixes pequenos ainda estão por ser descritos (Bohlke et al., 1978), é de supor-se que esta cifra, ou mesmo até uma maior, seja válida para os peixes amazônicos. Oitenta e cinco por cento desta fauna é composta por representantes da super-ordem Ostariophysi (Koberts, 1972), grupo que engloba a maioria dos peixes de água doce do mundo (cinco a seis mil espécies, segundo Greenwood et al., 1966; Géry, 1969). A família Anostomidae da sub-ordem Characoidei, endêmica da América do Sul, é constituída por 10 gêneros e mais de 100 espécies (Myers, 1950; Géry, 1977). São popularmente conhecidos como aracus na região amazônica e como piaus, piavusus, canivetes, solteiras, piaparas e taguaras, em outras regiões do Brasil (Magalhães, 1931; Godoy, 1975; Nomura, 1975) .

Embora a família e os gêneros sejam bem definidos sistemáticamente entre os Characoidei (Greenwod et al., 1966; Géry, 1977), ainda existem certas dúvidas a nível especifico (Géry, 1977; Garavello, comun. pessoal) sendo raríssimas as informações sobre biologia e ecologia das espécies.

O presente trabalho tem por objetivo analisar algumas características morfológicas. com base no exame de séries de indivíduos de vários tamanhos, para complementar o conhe. cimento da sistemática de três espécies de anostomídeos comuns na região de Manaus : Schizodon fasciatus Agassiz, 1829; Rhytiodus microlepis Kner 1859; e Rhytiodus argenteofuscus Kner, 1859. São analisados e discutidos também aspectos da morfologia do aparelho digestivo e variações do padrão de colorido das três espécies, nos diferentes estágios de desenvolvimento.

\section{MATERIAL E MÉTOL03}

Os peixes estudados foram coletados no lago Janauacá, situado entre as coordenadas geográficas de $3^{\circ} 20^{\prime}$ a $3^{\circ} 40^{\prime} \mathrm{S}$ e $60^{\circ} 10$ a $60^{\circ}$ $30^{\prime} \mathrm{W}$, localizado na margem direita do rio Solimões e distante cerca de $60 \mathrm{~km}$ de Manaus$A M$. É um lago de várzea, com água branca, mista e preta, dependendo do local e da época do ano (Santos, 1979).

As coletas foram feitas quinzenalmente, de abril de 1977 a abril de 1978, com o uso de maIhadeiras e redinhas, os dois aparelhos de pesca mais comuns e eficientes na região (Petrere Jr., 1978). Os peixes coletados foram deixados em formol a $8 \%$ por cerca de dois meses, lavados em água corrente e mantidos em álcool a $70 \%$.

\footnotetext{
(") - Parte da tese de Mestrado apresentada ao Curso de Pós-Graduação do Instituto Nacional de Pesquisas da Amazônia e Fundaçăo da Universidade do Amazcnas, em 1979.

("*) - Instituto Nacional de Pesquisas da Amazônia, Manaus.
} 
Como a maioria das descriçöes contidas em trabalho sobre sistemática de peixes de água doce da Amazônia, realizados no século passado e início deste, baseia-se quase sempre $\epsilon \mathrm{m}$ poucos exemplares adultos e já preservados, a identificação de um peixe recém-coletado ou de um jovem raramente é possível, pois, geralmente há variações consideráveis com o crescimento. Tendo inicialmente identificado os adultos com relativa facilidade com 0 auxílio das descrições existentes, o mesmo não aconteceu com os jovens, os quais apre. sentaram um padrão de colorido totalmente diferente. Não foi possível decidir na ocasião se os jovens capturados correspondiam às mes. mas espécies que os adultos ou a espécies diferentes, cujos adultos ainda não tinham sido coletados. Somente com o desenvolvimento posterior do trabalho e a coleta de séries com todos os tamanhos, foi possível constatar e definir a variação de colorido de cada espécie. Ficou patente que a forma, o número e a disposição das barras e máculas do corpo são muito importantes para a caracterização das espécies. Por este motivo não nos detemos somente no levantamento de caracteres tradicionais citados na literatura sistemática, mas procuramos dar ênfase à descrição do colorido, no decorrer do desenvolvimento, nas três es. pecies.

As descrições do padrão de colorido foram feitas com base no exame de exemplares a fresco, recém-coletados; as medidas morfométricas e cs dados merísticos foram tomados em exemplares preservados em álcool a $70 \%$ Observou-se que os padrões de colorido dos peixes preservados são idênticos aos dos peixes a fresco, apenas o colorido diminui de intensidade e as tonalidades verde e verde-amarelado tornam-se castanhas.

Os critérios adotados para as contagens e medidas e definições e comentários de determinadas estruturas e de certos termos citados no trabalho são relacionados abaixo.

Comprimento padrão - medido da ponta do focinho ao nível de contato dos raios caudais com a porção superior do pedúnculo caudal.

Escamas acima da linha lateral - fileira de escamas imediatamente anterior à nadadeira dorsal e contadas para baixo e para frente até a linha lateral, sem incluir a escama desta. Para a contagem foram utilizados 46 indivíduos de $S$. fasciatus, 53 de $R$. microlepis e 42 de $R$. argenteofuscus.

Escamas abaixo da linha lateral - fileira de escamas imediatamente anterior à nadadeira ventral, contadas para cima e para a frente, até a linha lateral, sem incluir a escama desta. Para a contagem foi utilizado o mesmo número de exemplares que o acima citado.

Raios das nadadeiras - foram contados os raios simples e ramificados. Os dois últimos raios das nadadeiras dorsal e anal, conectados entre si na base foram considerados como sendo apenas um. Foram utilizados para a contagem 34 indivíduos de $S$. fasciatus, 20 indivíduos de $R$. microlepis e 20 de $R$. argenteofuscus.

Rastros branquiais (Fig. 1) - Foram contados os rastros, inclusive os rudimentares, das porções superior, inferior e do ângulo, nas faces interna e externa do primeiro arco branquial esquerdo. Para a contagem foram utilizados 30 exemplares de vários tamanhos de $S$. fasciatus, 40 de $R$. microlepis e 34 de $R$. argenteofuscus.

Dentes faringeanos (Fig. 2) - Formam duas placas arredondadas superiores e uma triangular inferior, localizadas no início do esôfago e final da cavidade bucal, atrás e junto ao último arco branquial. Os dentes faringeanos das placas superiores são cônicos e têm a parte terminal aguda, com uma a três cúspides côncavas (Fig. 2) voltadas para trás. Os dentes das duas placas superiores foram contados juntos já que não apresentaram diferença em número. Os dentes da placa inferior, de mesmo formato que os das placas superiores, têm as cúspides voltadas para a frente. Para contagem, foram utilizados 42 exemplares de Schizodon fasciatus; 32 , de Rhytiodus microlepis e 32 de $R$. argenteofuscus, de vários tamanhos.

Comprimento do estômago - Medido com régua melimetrada, da porção anterior (final do esôfago) até o vértice e daí até o início do intestino, ao nível de origem dos cecos pilóricos. Para a contagem foram utilizados 183 exemplares de Schizodon fasciatus (83 jovens e 100 adultos), 155 exemplares de Rhytiodus 
microlepis (47 jovens e 108 adultos) e 40 exemplares de $R$. argenteofuscus (9 jovens e 31 adultos) .

Comprimento do intestino - Medido sobre régua melimetrada, da sua porção inicial até o nível da abertura anal, desfeitas as dobras, sem esticar. Para as medidas foram utilizados 194 indivíduos de Schizodon fasciatus (85 jovens e 109 adultos) 163 de $R$. microlepis (46 jovens e 117 adultos) e 44 exemplares de $R$. argenteofuscus ( 9 jovens e 35 adultos).

Cecos pilóricos (Fig. 9) - Estruturas arredondadas, individualizadas, mas aderidas umas às outras, com tamanho mínimo e máximo, respectivamente de 10 a $60 \mathrm{~mm}$ nos adul. tos, originando-se na porção inicial do intestino. Para as contagens foram utilizados 199 individuos de Schizodon fasciatus 112 e Rhytiodus microlepis e 37 de $R$. argenteofuscus, de vários tamanhos.

Coeficientes estomacal e intestinal - Respectivamente, a razão entre o comprimento do estômago e do intestino e o comprimento padrão do peixe, em milímetros.

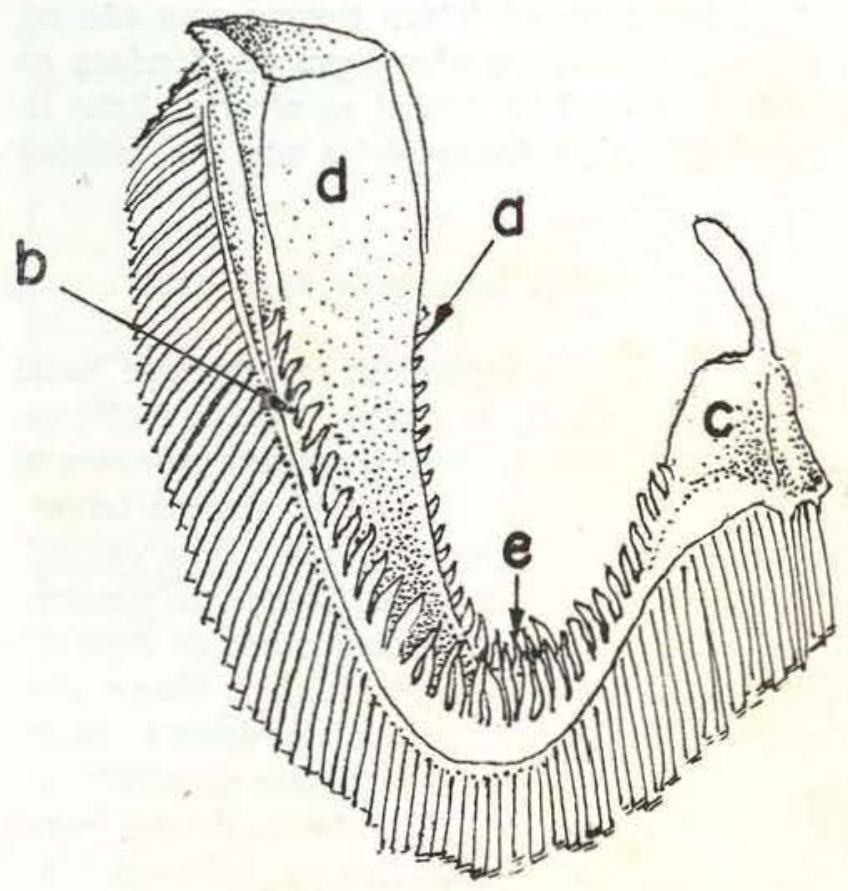

Fig. 1 - Disposiçāo dos rastros branquiais nas faces interna (a) e externa (b), nos ramos superior (c) e inferior (d) e no vértice (e) do primeiro arco branquial esquerdo.
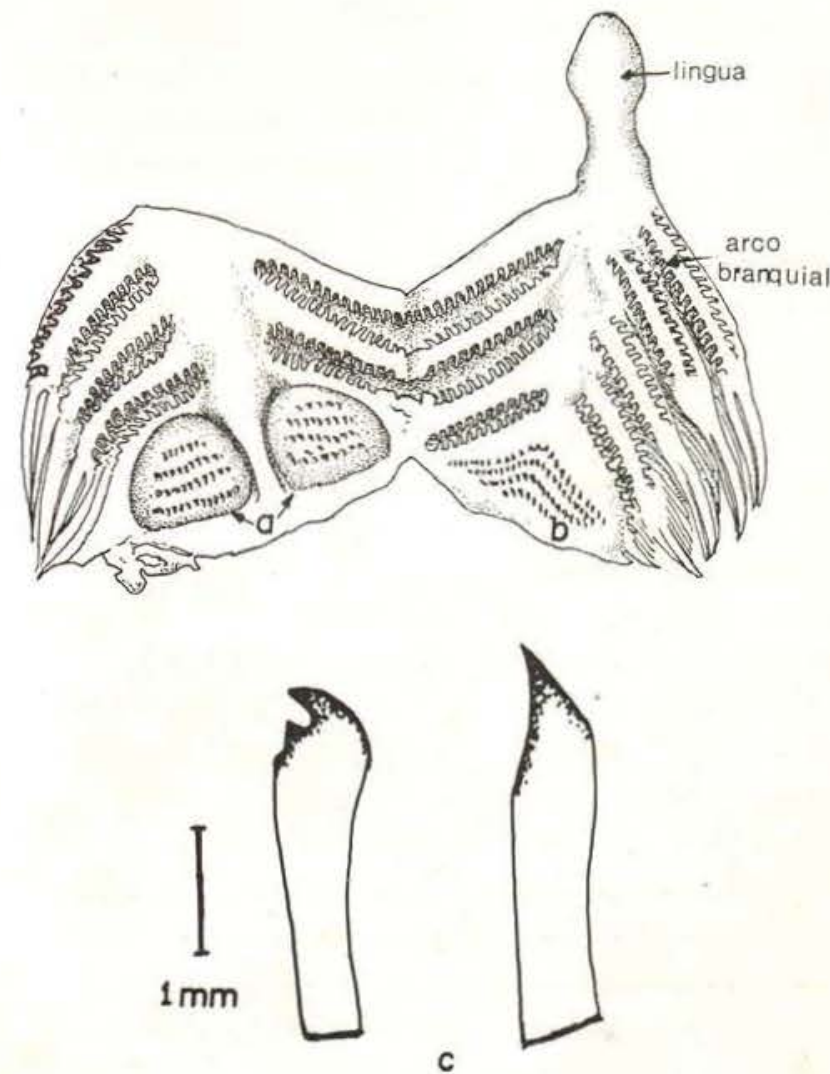

Fig. 2 - Disposição das placas faringeanas superiores (a) e inferior (b) e esquema ampliado das principais estruturas dos dentes faringeanos (c) nelas localizados.

Jovem - Indivíduo que ainda não se reproduziu (imaturo). Foi adotado como tamanho limite o ponto correspondente em que $50 \%$ dos indivíduos são imaturos e $50 \%$, maduros

Aduito - Indivíduo que já reproduziu. Como tamanho limite adotou-se aquele em que $50 \%$ dos peixes, amostrados săo imaturos e $50 \%$ maduros (Santos, 1979).

Amostras representativas de indivíduos em várias fases de desenvolvimento das três espécies encontram-se depositadas na coleção da Ictiologia do INPA, Manaus-AM.

\section{ReSUltados}

As contagens dos raios das nadadeiras dorsal, peitoral, ventral e anal, das escamas da linha lateral e acima e abaixo da linha lateral e o número e forma dos dentes do premaxilar de dentário (Tabela 1, Fig. 3, 4, 5) bem como outras características observadas, concordam com os valores obtidos e utilizados por Eigen- 
mann (1912), Schultz (1944) e Géry (19721973, 1977) para a caracterização e distinção das espécies. Além destas, consideramos também as coritagens dos rastros branquiais. dentes faringeanos e cecos pilóricos, que revelaram diferenças muito significativas entre as espécies (Tabela 1 Fig. 6, 7, 8). Uma diagnose diferencial das três espécies estudadas é esboçada a seguir.

\section{Schizodon fasciatus Agassiz, 1829}

Boca terminal, pequena, a amplitude bucaı maior que nas duas espécies de Rhytiodus. Dentes incisivos, côncavos do lado interno, tri ou tetracuspidados, as cúspides bem visiveis com bordos mais escuros (marrons) contrastando com a cor esbranquiçada do resto do dente. 8 dentes no premaxilar e 8 no dentário, decrescendo gradativamente de tamanho a partir dos mais anteriores para os mais posteriores $\in$ formando uma série única (Fig. 4, 5). Rastros branquiais (Fig. 1) moles, pequenos (máximo de $3,5 \mathrm{~mm}$ de comprimento), variando de 19 a 23 na face interna e de 21 a 26 na face externa. Dentes faringeanos (Fig. 2) arredondados, geralmente bi ou tri cuspidados, em números de 120 a 165 nas placas superiores e de 75 a 115 na placa inferior. Estômago (Fig. 9) em forma de "V"; porção anterior (cárdica) descendente, com paredes finas (cerca de 0,2 a $0,5 \mathrm{~mm}$ de espessura nos adultos) partindo do esôfago e estendendo-se até o vértice, de onde parte a porção ascendente (pilórica) mais estreita e menor que a anterior, com paredes relativamente mais espessas $(1,5$ a $2,0 \mathrm{~mm}$ de espessura nos adultos $€$ coeficiente estomacal médio de 0,38 e 0,47 nos jovens e adultos. respectivamente. Cecos pilóricos (Fig 9) partindo da região pilórica, recobrindo quase toda a porção ascendente do estômago, e, diminuindo de tamanho, estendendo-se até aproximadamente $1 / 6$ do comprimento do primeiro ramo do intestino; apresentam uma variação de 17 a 23 e média de 20,4 cecos. Intestino (Fig. 9) partindo da porção pilórica do estômago, descendo até pouco além do vértice do estômago, subindo até o nivel de sua origem e descendo novamente até o ânus, perfazendo um total de três voltas; apresenta um coeficiente intestinal médio de 1,25 e 1,44 nos jovens e adultos res- pectivamente. Os resultados dos caracteres analisados encontram-se nas Tabelas $1,2 \mathrm{e}$ Fig. 3-10.

\section{PADRÃO DE COLORIDO}

Exemplares com até cerca de $30 \mathrm{~mm}$ de comprimento padräo (Fig. 11A) apresentam o corpo sem manchas conspícuas ou com vestígios de manchas arredondadas escuras que correspondem às futuras máculas de indivíduos maiores ou às faixas transversais dos adultos. A nadadeira adiposa apresenta uma mancha amarelo-clara na parte central, circundada por uma coloração escura que se estende por toda a nadadeira. Em exemplares com cerca de $60 \mathrm{~mm}$ de comprimento padrão (Fig. 11-B) as manchas arredondadas sobre o corpo são mais nítidas e maiores, a primeira situando-se entre o opérculo e a nadadeira dorsal; a segunda, abaixo da dorsal; a terceira, entre a dorsal e a adiposa e a quarta, abaixo da origem da adiposa. A nadadeira adiposa tem uma coloração escura homogênea. Em exemplares adultos (Fig. 11-C) o corpo é prateado-acinzentado, um pouco mais escuro superiormente; as faixas transversais são ne gras e há uma mancha negra arredondada na base da nadadeira caudal ao nível da linha la. teral bem mais desenvolvida que nos estágios anteriores.

Rhytiodus microlepis Kner, 1859

Boca terminal, pequena, a ampitude bucal menor que em $S$. fasciatus. Dentes incisivos, delgados, frágeis, soltando-se ou quebrando-se com relativa facilidade; raiz deslocada lateralmente em relação ao eixo que passa verticalmente pelo meio do dente. Dentes do premaxilar, em número de oito, diminuindo de tamanho do mais anterior até o penúltimo, o último, consideravelmente menor que os demais, tendo cerca da metade do comprimento do penúltimo. Dentes da mandíbula, em número de oito, mais largos que longos, com uma projeçăo aguda situada lateralmente na parte côncava interna; aproximadamente do mesmo comprimento, exceto o último que tem cerca de $1 / 3$ do comprimento do penúltimo (Fig. 4 e 5 ). Rastros branquiais (Fig. 1) semelhantes aos da espé- 
Raios da nadadeira dorsal Raios da nadadeira peitoral Raios da nadadeira ventral Raios da nadadeira anal

$\begin{array}{ll}\text { Dentes } & \begin{array}{l}\text { pré maxilar } \\ \text { dentário } \\ \text { linha lateral } \\ \text { acima linha lateral } \\ \text { Escamas }\end{array} \\ & \text { abaixo linha lateral }\end{array}$

Cecos pilóricos

Rastros bran- face interna quiais face externa Dentes fa- placas superiores ringeanos
Rhytiodus microlepis

ytiodus argenteofuscus
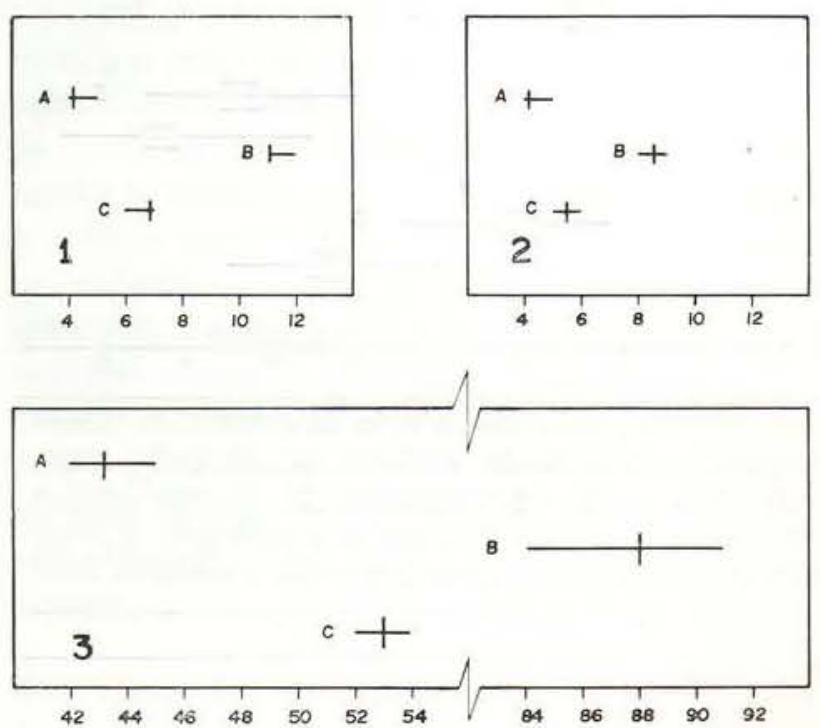

Fig. 3 - Amplitude da variação do número de escamas acima (1), abaixo (2) e ao longo (3) da linha lateral em Schizodon fasciatus (A), Rhytiodus microlepis (B) e R. argenteofuscus $(C)$. O traço vertical representa a média aritmética e o intervalo de confiança e a barra horizontal, a variação total.

cie anterior, variando de 29 a 34 na face interna e de 30 a 36 na face externa. Dentes faringeanos (Fig. 2) cônicos, geralmente unicuspidados, em número de 55 a 65 nas placas superiores e de 35 a 45 na placa inferior. Estômago e intestino (Fig. 9) com forma e estrutura semeIhante ao de $S$. fasciatus com coeficientes estomacal de 0,36 e 0,40 e intestinal de 1,26 e intestinal de 1,26 e 1,39 nos jovens e adultos, respectivamente. Cecos pilóricos (Fig. 9) ori. ginando-se na porção pilórica do estômago e estendendo-se ao longo do intestino até cerca da metade do comprimento do primeiro ramo descendente; apresentam uma variação de 50

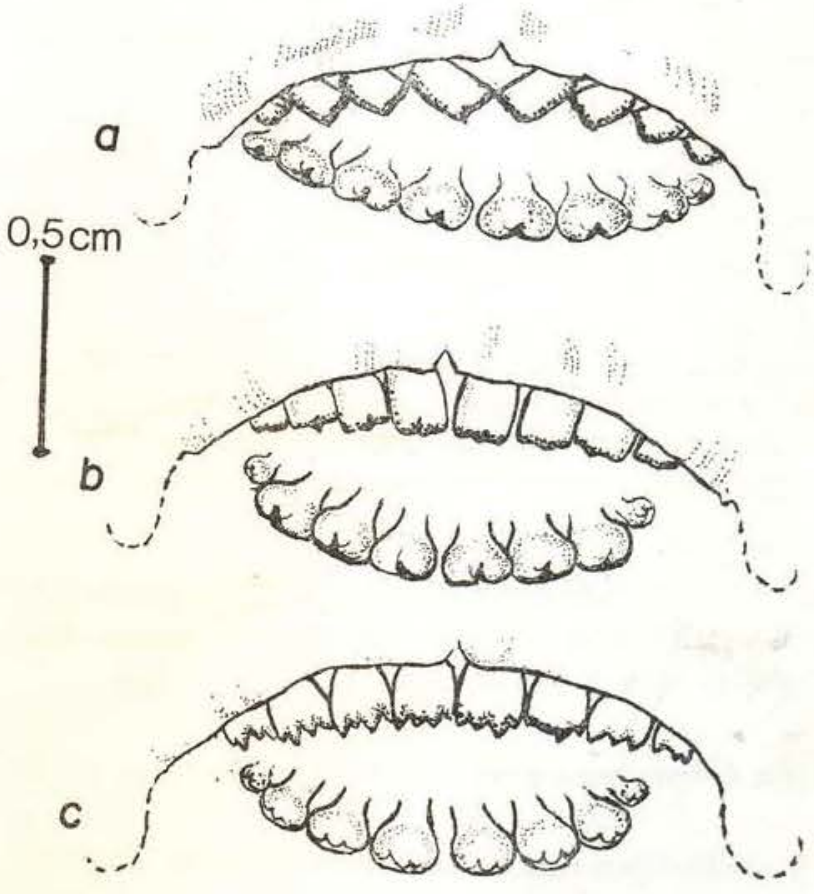

Fig. 4 - Disposição e estrutura dos dentes de maxila superior e inferior em Rhytiodus microlepis (a), R. argenteofuscus (b) e de Schizodon fasciatus (c), vistos de um ângulo ântero-superior. 


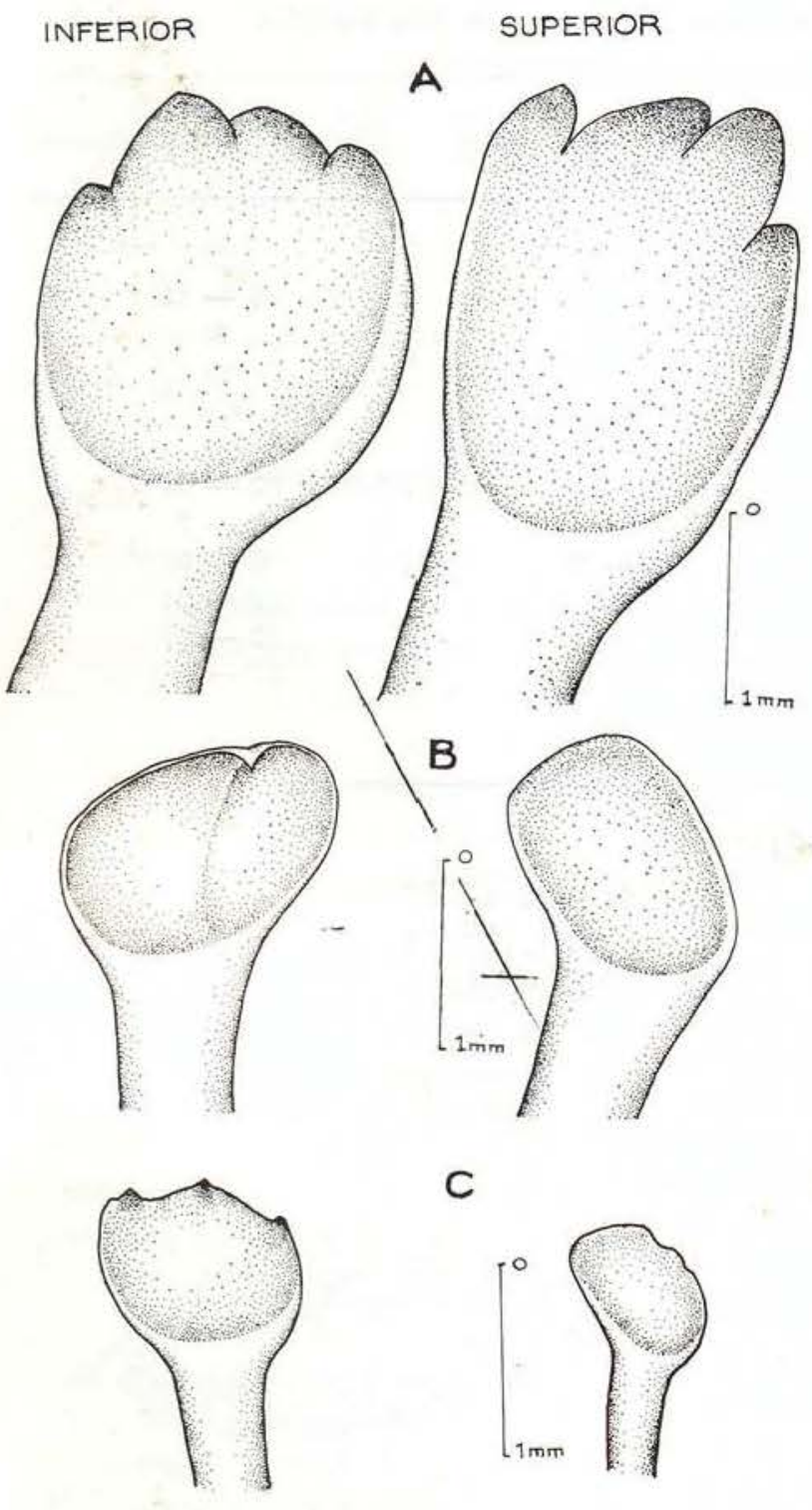

Fig. 5 - Vista frontal interna da estrutura dos dentes da maxila inferior e superior de Schizodon fasciatus (A),

Rhytiodus microlepis (B) e R. argenteofuscus (C).

a 65 e uma média de 55,6 cecos. Os resultados dos caracteres analisados encontram-se nas Tabelas 1 e 2 e Fig. 3-10.

PADRÃO DE COLORIDO

Indivíduos com cerca de 20 a $30 \mathrm{~mm}$ de comprimento padrão (Fig. 12-A,B) apresentam o corpo amarelo-esverdeado, com 8 a 10 faixas transversais castanhas, algumas anastomosadas, em forma de $\mathrm{K}, \mathrm{X}, \mathrm{H}$; a nadadeira adiposa tem uma mancha aiaranjada na parte central circundada por uma coloração escura que se estende por todo o resto da nadadeira. A porção anterior das nadadeiras dorsal e ventral é mais escura que a posterior; há um pequeno ponto escuro na base da cauda que não se estende além da base dos raios caudais medianos e uma faixa estreita escura longitudinal sobre o focinho que se estende da ponta da mandíbula à parte posterior do olho. Com cerca de $50 \mathrm{~mm}$ de comprimento padrão (Fig. 12-C) as características acima descritas praticamente se mantêm, todavia as faixas tornam-se mais nitidas e individualizadas, aparecendo um total de 13 a 15: 4 a 5 entre a parte posterior da cabeça e a origem da nadadeira dorsal, 2 sob

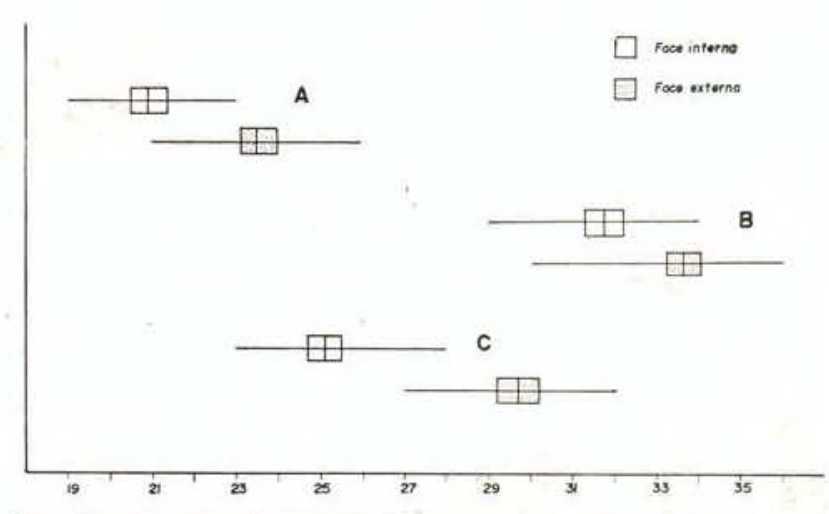

Fig. 6-Amplitude de variaçăo do número de rastros branquiais em Schizodon fasciatus (A), Rhytiodus microlepis (B) e em R. argenteofuscus (C). O traço vertical representa a média aritmética, e o retângulo, o intervalo de confiança e o traço horizontal, a variação total.

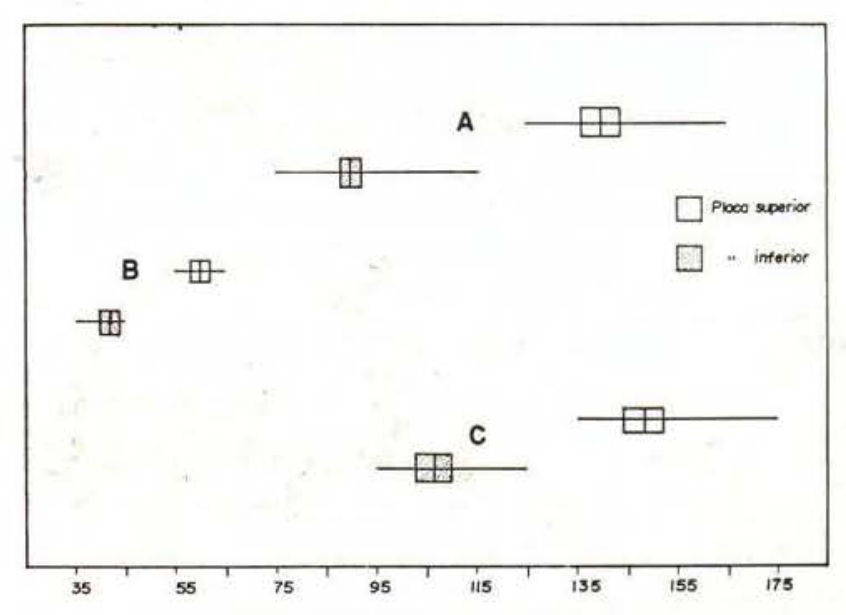

Fig. 7 - Amplitude de variação do número de dentes faringeanos em Schizodon fasciatus (A), Rhytiodus microlepis (B) e em R. argenteofuscus (C). Representaçăo como a da figura anterior. 


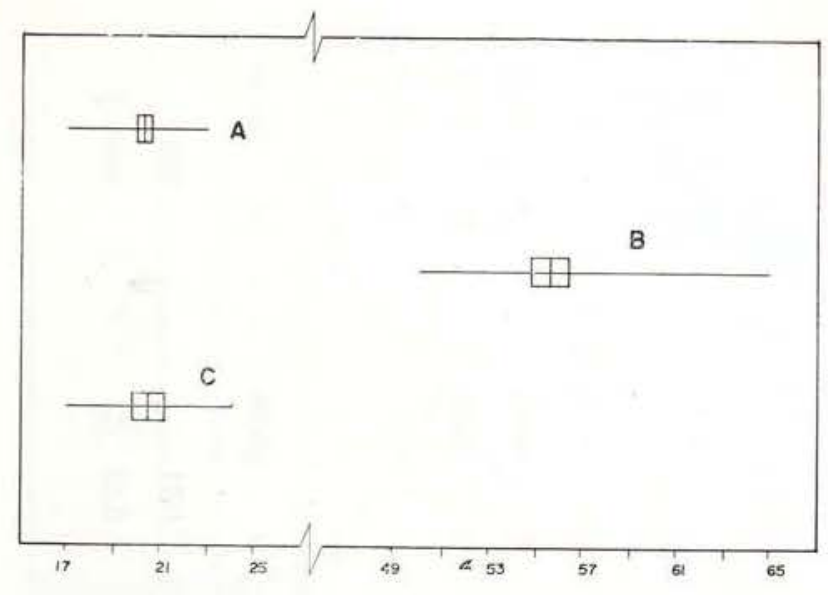

Fig. 8 - Amplitude de variação do número de cecos pilóricos em Schizodon fasciatus (A), Rhytiodus microlepis (B) e em R. argenteofuscus (C). O traço vertical representa a média aritmética; o retângulo, o intervalo de confiança e a barra horizontal, a variação total.

a dorsal, 5 a 6 entre a dorsal adiposa e 2 entre esta e a base da caudal. A partir de $80 \mathrm{~mm}$ de comprimento padrão (Fig. 12-D) as faixas vão se tornando menos nítidas e tendem a desaparecer; a mancha central alaranjada da adiposa e a faixa escura sobre o focinho desaparecem; as nadadeiras dorsal e ventral adquirem uma coloraçâo escura homogênea e o corpo torna-se marrom-escuro. Indivíduos com cerca de $120 \mathrm{~mm}$ de comprimento padrão já apresentam todas as características do aduito (Fig. 12-E), ou seja, perdem totalmente as faixas transversais, ficando o corpo com um colorido marromescuro.

NOTA

Géry (1972/73) descreveu três exemplares jovens $(2,53,0$ e $7,0 \mathrm{~cm}$ de comprimento padrãc) coletados no paraná Xiborena, nas proximidades de Manaus, como pertencendo possiveimente a um gênero novo de Anostomidae. Embora não atribuindo nome genérico, aquele autor reconheceu os três exemplares como distintos de todas as espécies incluídas nos gêneros até então descritos na família Anostomidae. Comparando os dados e a figura fornecidos por Géry com os que obtivemos para os exemplares jovens de R. microlepis observamos uma identidade quase total. Há apenas algumas discrepâncias com relação ao número de escamas na linha lateral, número de dentes

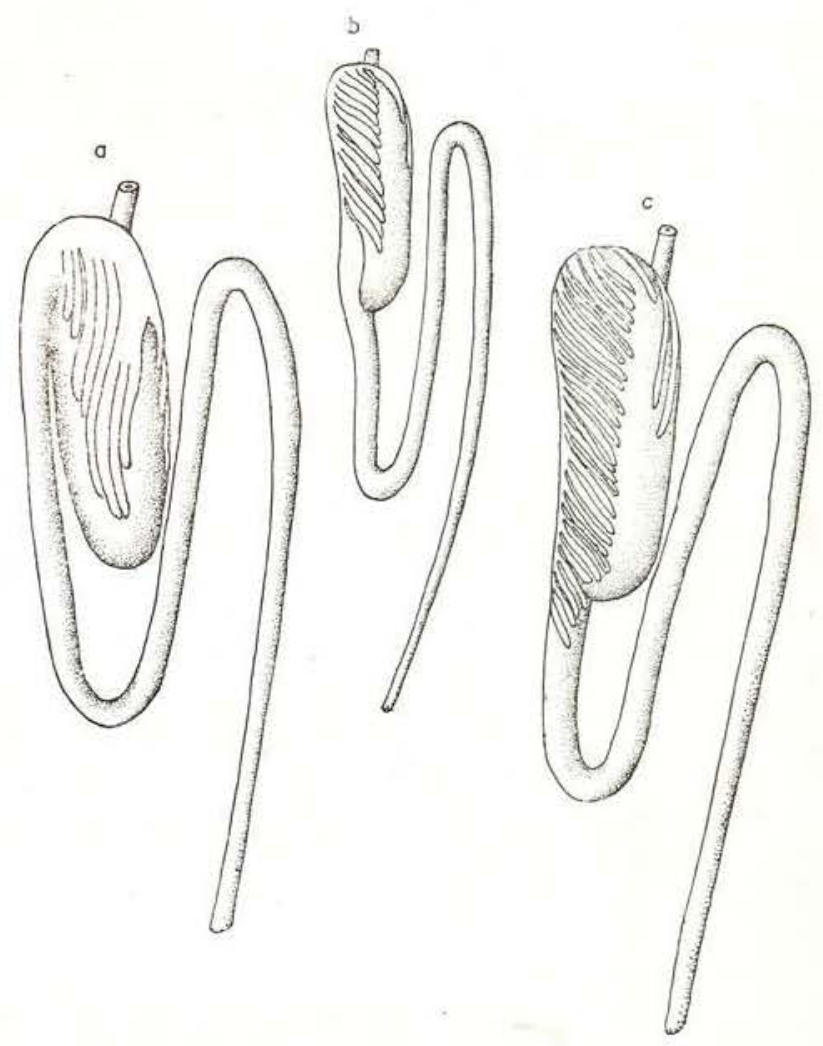

Fig. 9 - Disposição e estrutura esquemática do estômago, intestino e cecos pilóricos em Schizodon fasciatus (a), Rhytiodus argenteofuscus (b) e em R. microlepis (c).

do premaxilar e do dentário (respectivamente 70-72 e 6-6 segundo Géry). Com relação a estas contagens, entretanto, dificilmente obtémse dados precisos em exemplares jovens, pois as escamas e os dentes mais posteriores são muito pequenos, difíceis de serem contados, mesmo sob lupa. Além disso, os números relativos às escamas das pequenas depressões da pele onde ficam implantadas as escamas, pois estas, segundo aquele autor, estavam ausente nos exemplares examinados.

Posteriormente, analisando série de exemplares de vários tamanhos com o referido autor, chegamos a provar a real identidade daqueles espécimes como sendo de fato $R$. microlepis. Com a observação do padrão de coloriao e com o cálculo da alometria (Santos \& Géry, em preparação) foram mostradas certas variações no decorrer do ciclo ontogenético importantes para a segura identificação e caracterização da espécie. 
TABELA 2 - Freqüência absoluta e relativa, média $(x)$ e desvio padrão (s) dos coeficientes intestinal e estomacal de jovens e adultos das três espécies estudadas

\begin{tabular}{|c|c|c|c|c|c|c|c|c|c|c|c|c|}
\hline \multirow[b]{3}{*}{ COEFICIENTE INTESTINAL } & \multicolumn{4}{|c|}{ SCHIZODON FASCIATUS } & \multicolumn{4}{|c|}{ RHYTIODUS MICROLEPIS } & \multicolumn{4}{|c|}{ RHYTIODUS ARGENTEOFUSCUS } \\
\hline & \multicolumn{2}{|c|}{ Jovem } & \multicolumn{2}{|c|}{ Adulto } & \multicolumn{2}{|c|}{ Jovem } & \multicolumn{2}{|c|}{ Adulto } & \multicolumn{2}{|c|}{ Jovem } & \multicolumn{2}{|c|}{ Adulto } \\
\hline & n. & $\%$ & $\mathrm{n} .^{\circ}$ & $\%$ & $\mathrm{n} .^{\circ}$ & $\%$ & n. & $\%$ & $\mathrm{n} .^{\circ}$ & $\%$ & n.: & $\%$ \\
\hline $1,05 \longmapsto 1,15$ & 13 & 15,29 & - & - & 7 & 15,22 & - & - & 2 & 22,22 & 10 & 28,57 \\
\hline $1,15 \longmapsto 1,25$ & 37 & 43,53 & 3 & 2,75 & 16 & 34,78 & 15 & 12,82 & 2 & 22,22 & 9 & 25,71 \\
\hline $1,25 \longmapsto 1,35$ & 20 & 23,53 & 17 & 15,60 & 17 & 36,96 & 25 & 21,37 & 2 & 22,22 & 3 & 8,57 \\
\hline $1,35 \vdash 1,45$ & 12 & 14,12 & 37 & 33,95 & 4 & 8,70 & 41 & 35,04 & 3 & 33,34 & 2 & 5,71 \\
\hline $1,45 \longmapsto 1,55$ & 3 & 3,53 & 42 & 38,53 & 1 & 2,17 & 34 & 29,06 & - & - & 8 & 22,86 \\
\hline $1,55 \longmapsto 1,65$ & - & - & 10 & 9,17 & 1 & 2,17 & 2 & 1,71 & - & - & 3 & 8,57 \\
\hline TOTAL & 85 & 100,00 & 109 & 100,00 & 46 & 100,00 & 117 & 100,00 & 9 & 100,00 & 35 & 99,99 \\
\hline $\mathrm{x}$ & \multicolumn{2}{|c|}{1,25} & \multicolumn{2}{|c|}{1,44} & \multicolumn{2}{|c|}{1,26} & \multicolumn{2}{|c|}{1,39} & \multicolumn{2}{|c|}{1,28} & \multicolumn{2}{|c|}{1,30} \\
\hline s & \multicolumn{2}{|c|}{0,10} & \multicolumn{2}{|c|}{0,09} & \multicolumn{2}{|c|}{0,10} & \multicolumn{2}{|c|}{0,10} & \multicolumn{2}{|c|}{0,11} & \multicolumn{2}{|c|}{0,17} \\
\hline
\end{tabular}

COEFICIENTE ESTOMACAL

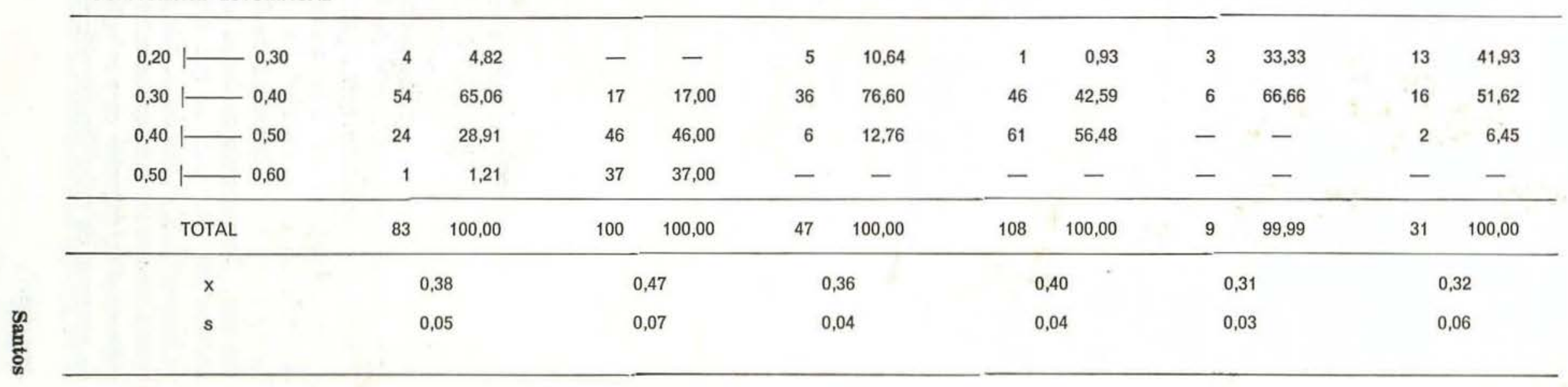



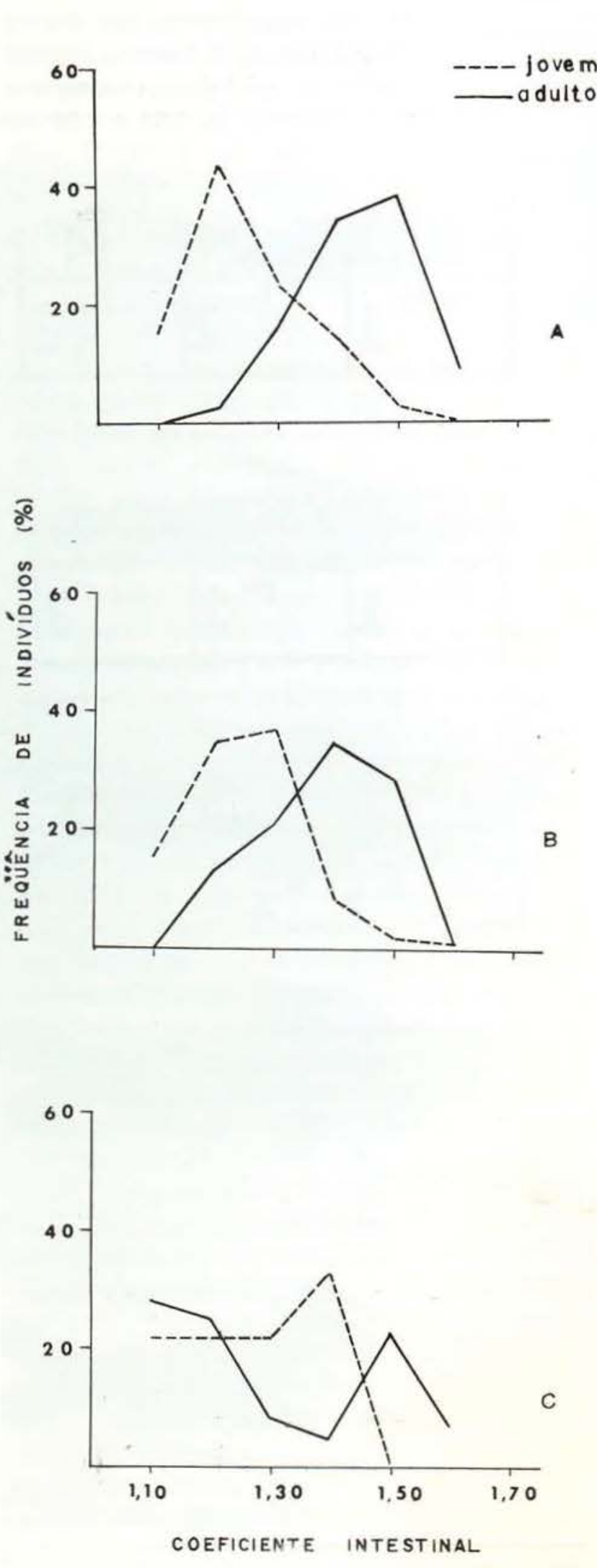
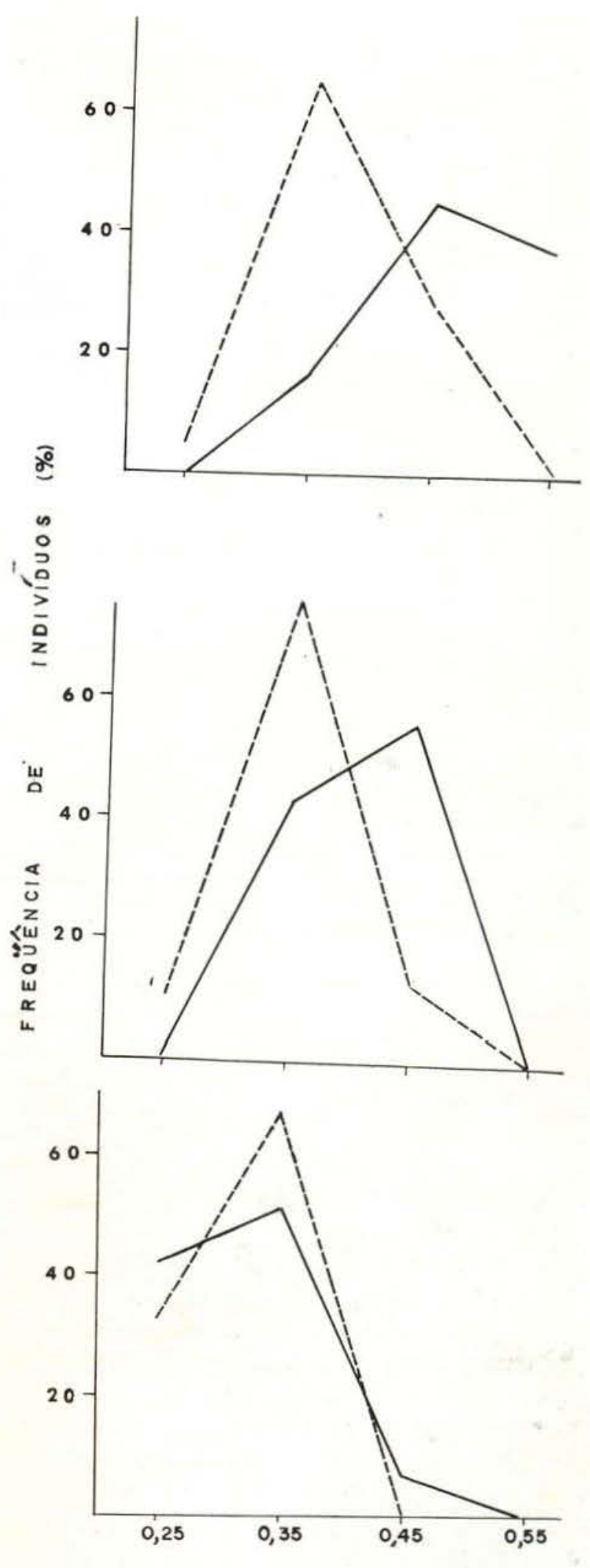

COEFICIENTE ESTOMACAL

Fig. 10 -Frequiência relativa dos coeficientes estomacal e intestinal de jovens e adultos de Schizodon fasciatus (A). Rhytiodus microlepis (B) e R. argenteofuscus (C).

Aspectos...

$-643$ 


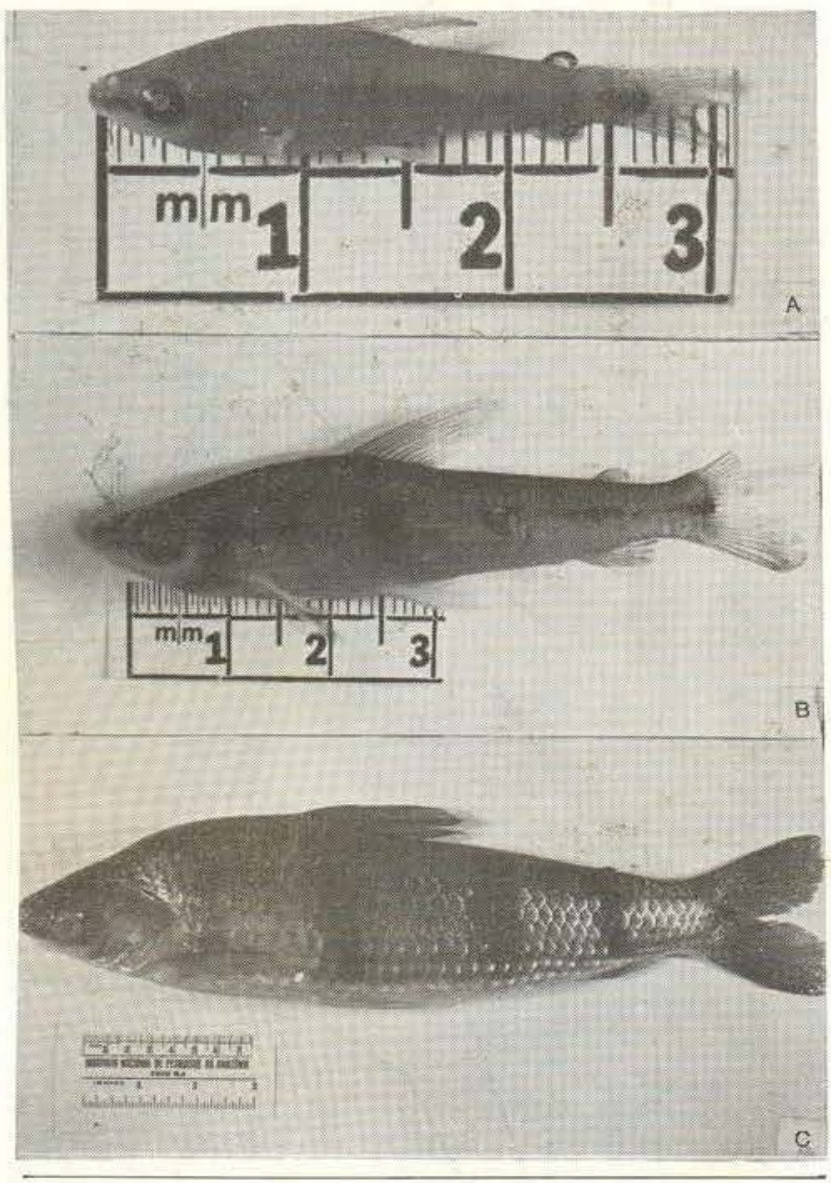

Fig. 11 - Variação ontogenética do padrão de colorido em Schizodon fasciatus. A, B, C - indivíduos com cerca de 30,60 e 300 milímetros de comprimento padrão, respectivamente.

\section{Rhytiodus argenteofuscus}

Boca terminal, pequena, amplitude bucal menor que na espécie anterior. Dentes premaxilares em número de oito, semelhantes quanto à forma e disposição aos de R. microlepis, com margens lisas ou apresentando pequenas fendas que, entretanto, não chegam a formar verdadeiras cúspides; último dente do premaxilar com cerca de $1 / 3$ do tamanho dos da sínfise. Dentes da mandíbula estruturalmente idênticos aos de R. microlepis, mas com projeções menos pronunciadas e em número de 1 a 2 em cada dente (Fig. 4 e 5). Rastros branquiais (Fig. 1) semelhantes aos das outras duas espécies, variando em número de 23 a 28 na face interna e de 27 a 32 na face externa. Dentes faringeanos (Fig. 2) cônicos, geralmente bi ou tricuspidados, 135 a 175 nas placas superiores e 95 a 125, na inferior. Estômago e intestino (Fig. 9) semelhantes aos das ou tras duas espécies, quanto à forma e disposi ção, apresentando os coeficientes estomacal de 0,31 e 0,32 e intestinal de 1,28 e 1,30 nos

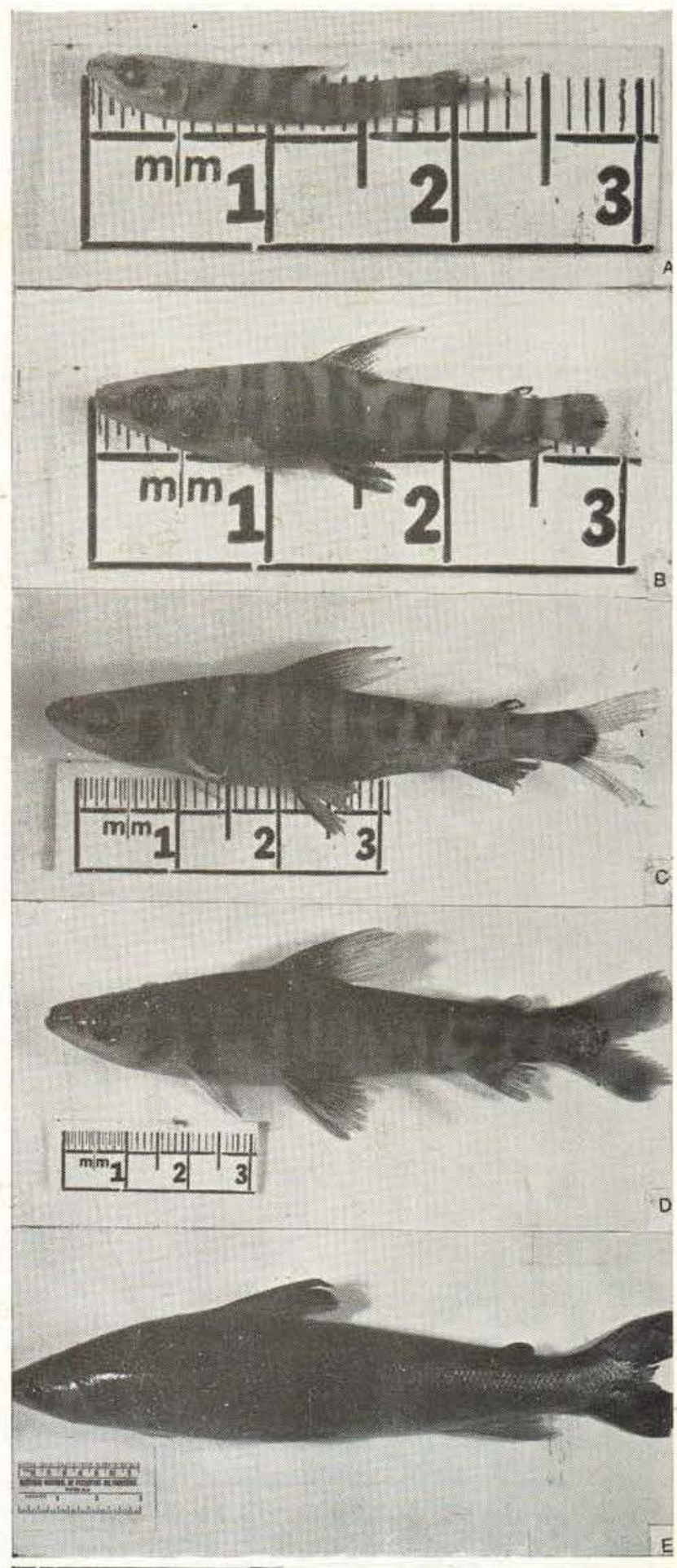

Fig. 12 - Variação ontogenética do padrão de colorido em Rhytiodus microlepis. A, B, C, D, E - individuos com cerca de $20,30,50,80$ e 350 milímetros de comprimento padrão, respectivamente. 
jovens e adultos, respectivamente. Cecos pilóricos (Fig. 9) com distribuição intermediária em relação à das duas outras espécies anteriormente citadas, isto é, originando-se na região pilórica e estendendo-se até aproximadamente o primeiro terço do primeiro ramo intestinal. Os resultados dos caracteres analisados encontram-se nas Tabelas 1,2 e Fig. 3-10.

\section{PADRÃO DE COLORIDO}

jovens com até cerca de $40 \mathrm{~mm}$ de comprimento padrão (Fig. 13-A) têm um padrão colorido muito semelhante ao que aparece nos jovens de $R$. microlepis até aproximadamente $50 \mathrm{~mm}$ (Fig. 12-C). O número (13 a 15) e a posição das faixas transversais e o colorido são também idênticos aos de R. microlepis. Apresentam 4 a 5 faixas entre a parte posterior da cabeça e a origem da nadadeira dorsal, 2 sob a dorsal, 5 a 6 entre a dorsal e a adiposa e 2 entre esta e a base da nadadeira caudal. A nadadeira adiposa também apresenta a parte central alaranjada, circunda. da por coloração escura. As nadadeiras dorsa! e ventral tem suas paries anteriores com coloração mais escura que suas partes posteriores. Há uma faixa longitudinal escura estreita sobre o focinho; a base da cauda apresenta uma mancha escura que se estende até a extremidade dos raios caudais medianos, contrariamente ao que ocorre nos jovens de $R$. microlepis em que não vai além do meio dos raios. Com cerca de $60 \mathrm{~mm}$ de comprimento padrão (Fig. 13-B) as características acima são mantidas, mas as faixás transversais vão se duplicando e adquirindo a forma de $K, Y, H$, sendo interrompidas no meio por manchas arredondadas escuras. Com cerca de $90 \mathrm{~mm}$ de comprimento padrão (Fig. 13-C) as manchas arredondadas vão se alongando e, fundindo-se umas às outras, seccionam longitudinalmente as faixas transversais (em número de 25, duplicadas e em face de desaparecimento) ao nível da linha lateral, formando uma faixa contínua que vai do opérculo à base da nadadeira caudal; a faixa sobre o focinho, a coloração central alaranjada da adiposa e a coloração mais escura da porção anterior da dorsal e da ventral desaparecem. Além desse tamanho os indivíduos já apresentam o padrão de colorido típico do adulto (Fig. 13-D), sobressaindo a taixa longitudinal escura do corpo, ao nível da linha lateral; o corpo apresenta um colorido verde-escuro acima daquela faixa longitudinal e prateado com manchas es curas esparsas, abaixo dela.

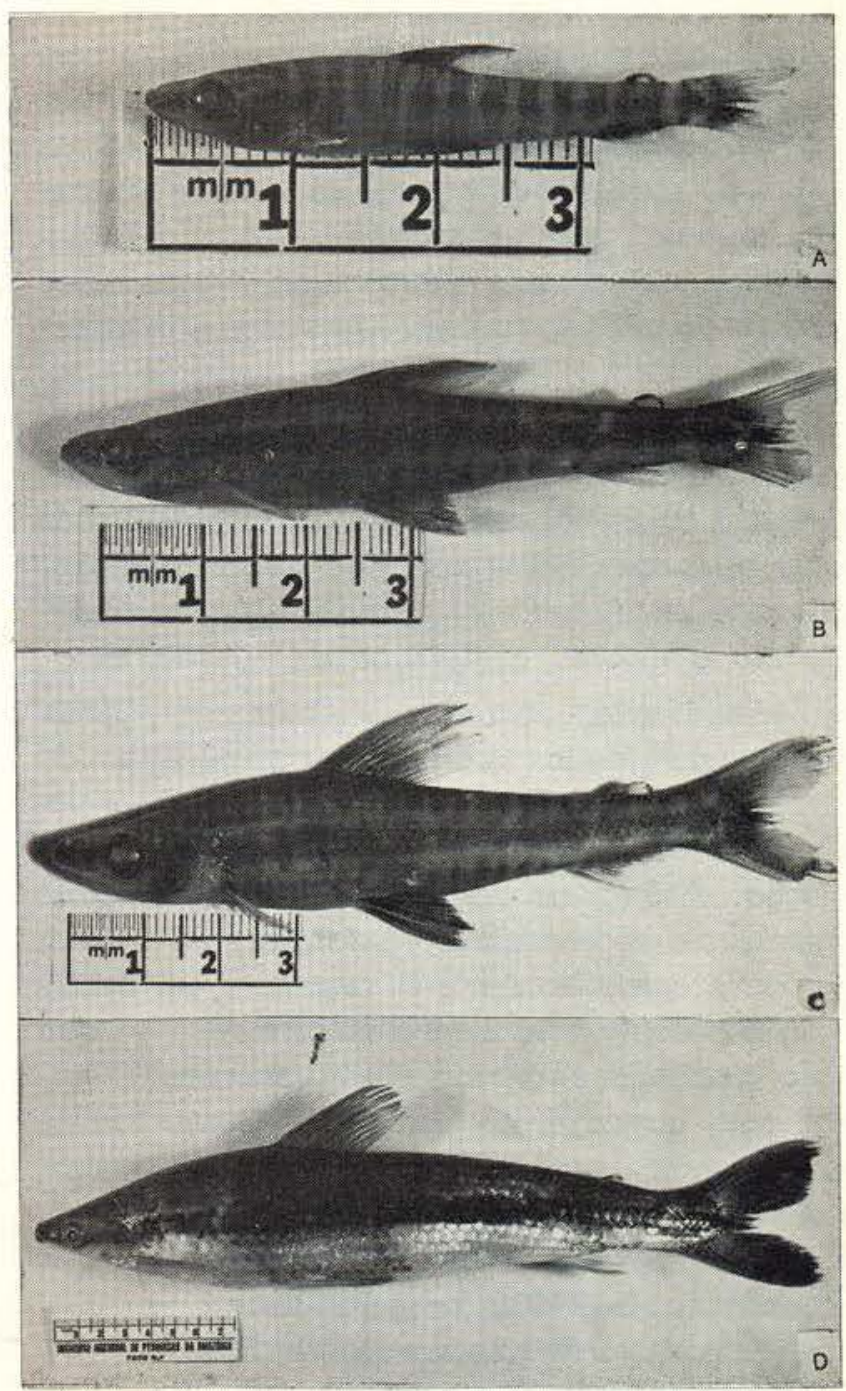

Fig. 13 - Variação ontogenética do padrão de colorido em Rhytiodus argenteofuscus. A, B, C, D - individuos com cerca de $40,60,90$ e 270 milimetros de com. primento padräo, respectivamente.

\section{DISCUSSÃO E CONCLUSÕES}

Apesar da família Anostomidae ser um dos grupos mais bem definidos entre os Characoidei sul-americanos, há dúvidas e problemas a nível específico, sobretudo com relação aos primeiros estágios de desenvolvimento dos indivíduos. É notório o grau de semelhança do padrão de colorido entre os jovens das duas 
espécies de Rhytiodus (e de diferença entre os jovens dessas espécies com os respectivos adultos); sendo realmente difícil uma distinção entre eles. Além disso, alguns caracteres básicos não diferem nas duas espécies (como raios das nadacleiras e número de dentes) ou são difíceis de serem visualizados mesmo com uso de lupa (como as escamas). O levantamento cuidadoso e a citação desses caracteres além de outros anatômicos, serviram pará meihor definir e bem separar as três espécies, em todos os estágios de crescimento, alguns deles indicando certo grau de relação com a natureza da alimentação (Santos, 1979) .

É importante, pois, que tanto no estudo de aspectos sistemáticos quanto biológicos os peixes sejam considerados e caracterizados nos seus diferentes estágios de crescimento visando uma meihor determinação, conhecimento e mesmo exploração das espécies.

Analisados sob o aspecto alimentar, verifica-se que muitos caracteres anatômicos do trato digestivo considerados aparentam ter relação direta e clara com a natureza da alimentação. Assim, os dentes da maxila como da mandíbula são multicuspidados, desenvolvidos, grossos e robustos em $S$. fasciatus em oposição aos dentes das espécies de Rhytiodus que são destituídos de cúspides verdadeiras, pequenos, largos, finos e frágeis. Como S. fasciatus tem uma alimentação à base de folha, caule e raízes de capins aquáticos e as espécies de Rhytiodus, principalmente de algas e raízes (Santos, 1979), observa-se que por possuirem dentes menos resistente, $R$. microlepis e $R$. argenteofuscus alimentam-se de partes mais tenras, ocorrendo o oposto com S. fasciatus. Este fato é corroborado pelo fato dos itens estomacais das espécies de Rhytiodus encontrarem-se geralmente inteiros e os de $S$. fasciatus, geralmente cortados.

O arranjo, a estrutura e o tamanho dos rastros branquiais, citados em material e métodos, são semelhantes nas três espécies. Estas estruturas têm uma função importante na a!imentação (Lagler, 1962; Storer \& Usinger, 1974). Contrariamente ao que ocorre nos peixes carnívoros onde os rastros são geralmente fortes e com espinhos ou nos planctólagos onde eles são muitos longos e numerosos, nos
Anostomídeos estudados, aparentemente eles näo têm grande funcionalidade na tomada do alimento; este e outros exemplos observados com outras espécies parecem indicar que peixes herbivoros ou omnivoros com predominân. cia herbivora possuem rastros branquiais moles, não especializados ou seja, não atuando diretamente na alimentação.

Os dentes faringeanos desempenham preponderante papel na alimentação dos Cyprinoidei (Wunder, 1936; Harder, 1964 apud Knopel, 1970) e devido ao alto grau de adaptação e especialização adquirido representam um importante caráter para a diferenciação genérica e específica do grupo. Em Characoidei os dentes faringeanos ainda não foram suficientemen. te estudados. Segundo Roberts (1973) a maioria dos Characoiciei apresentam dentes faringeanos cônicos e unicuspidados, exceto Anostomidae e outros poucos grupos altamente especializados que os apresentam multicuspidados. De acordo com os resultados obtidos da análise das espécies tratadas neste trabalho, observou-se no entanto que dentes faringeanos uni a tricuspidados ocorrem num mesmo indivíduo, nas três espécies, havendo apenas predominância de um só tipo de dentes em cada espécie (veja descrição das espé. cies).

Apesar da grande variação total do número desses dentes, devido possivelmente ao fato de muitos deles aparecerem caídos ou gastos pelo uso, a sua estrutura e disposição nas três placas faringeanas aparentam ter clara relação com a alimentação, criando condições para dilaceraçāo do alimento ingerido: as placas superiores (duas) e inferior (uma) que sustentam os dentes faringeanos entram em contacto a um mesmo nível, tendo as superiores dentes com as concavidades das cúspides dispostas em sentido retrorso, em oposição aos da placa inferior que tem as concavidades das cúspides voltadas para frente. O movimento de vai-e-vem efetuado pela ação dos músculos naquela região ou até mesmo a simples passagem do alimento por entre elas, fazem com que este sofra um esmagamento ou dilaceração.

$\mathrm{O}$ tamanho e a estrutura do trato digestivo (estômago e intestino) são considerados por muitos autores, como Angelescu \& Gnery, 
1949; Lagler, 1962; Nikolski, 1963 e Kruger et al. s. d., como tendo uma estreita correla. ção com natureza da alimentação, verificando. se que os peixes carnívoros apresentam n estômago muito fino e distendivel e coeficiente intestinal pequeno; os peixes iliófagos e herbívoros, possuem estômago grosso, pouco distendivel e um grande coeficiente intestinal os peixes omnivoros apresentam características intermediárias às dos dois tipos citados.

Como há um certo erro de medida causado pela impossibilidade de um controle ou padro. nização na distenção do trato digestivo, tornase difícil uma quantificação precisa desta medıda, mas esta falta de precisão é diminuída quando se analisa uma amostra de tamanho adequado, não tirando, pois, o mérito e a importância dos coeficientes estomacal e intestinal que constituem significativos indicadores das tendências gerais dos hábitos alimentares.

Foi observado que as espécies aqui tratadas apresentaram um trato digestivo seme. Ihante estruturalmente: estômago em forma de "V" e intestino perfazendo três voltas (Fig. 9): os valores dos coeficientes estomacal e intestinal (Fig. 10) indicam que as 3 espécies têm um trato digestivo (estômago e intestino) de tamanho muito semelhante. Observa-se ainda na mesma figura que estes coeficientes são reiativamente maiores nos adultos que nos jovens de cada espécies.

Veregina \& Medani (1968) citam duas espécies de Characoidei (Distichodus niloticus e D. rostratus), africanas ambas herbivoras, com estômago em forma de " $\mathrm{V}$ ", intestino formando 3 voltas e coeficiente intestinal de 2,77 e 2,31, respectivamente; Hickling (1966, apud Veregina \& Medani 1968) apresenta Ctenopharyngodon idella, um Cyprinoidei também herbívoro com um coeficiente intestinal de 2,30; Honda (1974) cita Colossoma bidens, peixe amazônico preponderantemente herbívoro, com um coeficiente intestinal, de 2,0 a 2,5 . Comparadas, pois, com as espécies herbívoras citadas, as espécies estudadas apresentaram estrutura e tamanho do trato digestivo muito semelhantes.

Os cecos pilóricos, considerados como tendo função na digestão e/ou absorção dos alimentos (Lagler, 1962; Alves, 1970), ocorrem em muito maior número em Rhytiodus microle- pis (50 a 65) que nas duas outras espécies (17 a 24), constituinco-se assim, num dos mais adequados caracteres de diferenciação entre as duas espécies de Rhytiodus. Knoppel (1970) estudou a alimentação de cerca de 50 espécies de peixes amazônicos; todas elas consideradas por sste autor como "não especialistas" quan. to ao regime alimentar, apresentaram um número máximo de 12 a 16 cecos pilóricos; $\mathrm{Ba}$ seado nestas informações e considerando que as três espécies aqui tratadas podem ser consideradas como "especialistas", alimentandose de material vegetal, é de supor que o maior número de cecos pilóricos tenha relação direta com o regime vegetariano.

Considerando-se que as três espécies têm um regime alimentar especializado, à base de material de origem vegetal, apresentando-se com pequeno grau de especificidade por folha. e caule de capins aquáticos em Schizodon fasciatus e por algas e raízes nas espécies de Rhytiodus e associando este fato às características do trato digestivo analisadas, observase que existe uma diferença acentuada com relação à dentição: dentes mais fortes, desenvolvidos e com mais cúspides em Schizodon fasciatus e usados principalmente para "cortar" em oposição aos de Rhytiodus, usados principalmente para "puxar" o alimento. Observa-se ainda que ao maior número de cecos pilóricos em Rhytiodus microlepis corresponde um maior número de dentes faringeanos em Rhytiodus argenteofuscus; possivelmente estas estruturas atuam como meios mutuamente compensatórios, favorecendo uma melhor utilização da fonte alimentar que é comum às duas espécies (Santos, 1979).

O padrão de colorido é importante para a caracterização das espécies de Leporinus, gênero de Anostomidae dominante em número de espécies e de mais ampla distribuição geográfica na América do Sul (Géry, 1977; Britski \& Garavello, 1978). Nas espécies de Schizodon e Rhytiodus tratadas neste trabalho, o padrão de colorido, apesar de sofrer profundas transformações com o decorrer do ciclo ontogenéti. co, mostrou-se característico para cada espécie, servindo para diferenciá-las e determinálas. Nas espécie de Rhytiodus há uma tendência das bandas transversais dos jovens evolui- 
rem para bandas longitudinais ou mesmo desaparecerem nos adultos; em Schizodon fasciatus, por outro lado, as bandas transversais se acentuam à medida que o peixe cresce.

A presença da mancha clara no centro da nadadeira adiposa, como um ocelo, na fase juvenil das três espécies, é um fato relevante pois pode ser interpretado como tendo alto significado bio-ecológico. Géry (1960, apud Lowe-McConnell, 1964) considera a presença do ocelo nos peixes como uma característica importante para o reconhecimento específico ou sexual. Wickler (1970, apud Zaret, 1977) considera o ocelo como tendo função nas relações entre presas e predadores. O instinto de defesa é sempre acentuado em todas as fases de desenvolvimento de um peixe, mas talvez nos jovens, devido à mobilidade ainda incipiente, o ocelo seja particularmente importante como meio de defesa, compensando assim a pequena capacidade de fuga. Como nas espécies aqui tratacias o ocelo só aparece na fase juvenil, conclui-se que este deve desempenhar impcrtante papel no equilibrio das relaçōes destes peixes com seu ambiente. Para os peixes predadores que tomam suas presas geralmente pela cabeça, a posição do ocelo na parte posterior do corpo destas é crítica, uma vez que o ocelo é interpretado como um olho, o o que beneficia a presa em caso de ataque pelo predador.

A extraordinária semelhança aparente entre cs jovens de Rhytiodus com até cerca de $60 \mathrm{~mm}$ de comprimento padrão parece ter importante papel como mecanismo mimético em que $R$. argenteofuscus, que ocorre em densidade muito menor no Janauacá, esteja "copiando " o padrão de colorido de $R$. microlepis, uma espécie de densidade populacional bem maior que aquela. Isso é corroborado pelo fato desses jovens aparecerem em cardume, sob os capins aquáticos e os adultos viverem solitariamente, além das duas espécies terem a mesma distribuição geográfica, isto é, só ocorrerem na bacia amazônica.

\section{AGRADECIMENTOS}

Agradecemos ao Dr. Naércio de A. Menezes, pela orientação e correção do manuscrito; ao Dr. J. Géry, pelas sugestões; aos Drs. H
Britski, Michael Goulding, Nigel Smith, J. C. Garavello e Sérgio Anibal, pelos comentários do texto; ao Dr. W. J. Junk, pelo incentivo e apoio.

\section{SUMMARY}

Variations in the colour patterns at different stages of development of Schizodon fasciatus, Rhytiodus microlepis and R. argenteofuscus are detailed. Various meristic and morphological characters, are analysed to give a more complete characterization of these species. The identification of the strange post-larval juvenile of R. microlepis once considered to be a separate genera within the Anostomidae, is discussed.

\section{BIBLIOGRAFIA}

ALVES, M.I.M. \& ToMÉ, G.S.

1970 - On the pyloric caeca in fishes of the genus Scomberomorus Lacépede. Arq. Ciênc. Mar. 10 (2): 181-184.

ANGelescu, V. \& GNERI, F.S.

1949 - Adaptaciones del aparato digestivo al régimen alimentício en algunos peces del Rio Uruguay y del Rio de La Plata: I - Tipo omnívoro e iliófago en representantes de las Famílias Loricariidae y Anostomidae. Rvta. Inst. Nac. Invest. Ciênc. Nat., 1 (6): 161-272.

BohlKe, J.E.; WeITZMan, S.H. \& MeNezes, N.A.

1978 - Estado atual da sistemática dos peixes de água doce da América do Sul. Acta Amazonica, 8 (4): 657-677.

BritsKi, H.A. \& GaRAVEllo, J.C.

1978 - Sobre Leporinus octafasciatus Steindachner da Bacia do Paraná (Pisces, Anostomidae). Papéis Avulsos Zool São Paulo, 31 (16): 237-250.

EigfnManN, C.H

1912 - The freshwater fishes of Britsh Guiana, including a study of the ecological grouping of species and the relation of the plateau to that of the lowlands. Mem. Carneg. Mus., 5 (1): 1-578.

GéRY, J.

1969 - The freshwater fishes of South América In: Fittkau, E.J., Illies, J; Klinge, H.; Schwabe, G.H. \& Sioli, H. eds. Biogeography and Ecology in South America. Hague, W. Junk N.V. Publishers. v. 2: 828-848

1972/1973 - Notes sur quelques Anostomidae (Pisces, Characoidei) du Bassin Amazonien. Vie Milien, Sér. C, 23 (1): 143-175.

1977 - Characoids of the world. TFH Publications, Inc. Neptune city: 672p. 
GODOY, M.P. DE

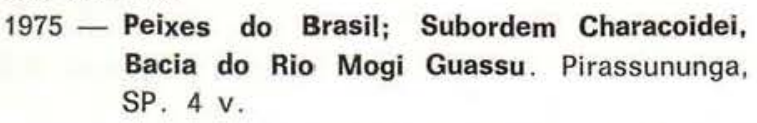

GReenwood, P.H.; Rosen, D.E.; WeItzMan, S.H. \& MYERS, G.S.

1966 - Phyletic studies of Teleostean Fishes, with a provisional classification of living forms. Bull. Am. Nat. Hist., 131 (4): 341-455.

HONDA, E.M.S.

1974 - Contribuição ao conhecimento da biologia de peixes do Amazonas. II. Alimentação do tambaqui, Colossoma bidens (Spix). Acta Amazonica, 4 (2): 47-53.

KNOPPEL, H.A.

1970 - Food of Central Amazonian Fishes. Contribuition to the Nutrient-Ecology of Amazonian Rain-Forest-Streams. Amazoniana, 2 (3): $257-352$,

KRUGER, E.J. \& MULDER, P.F.S.

s.d. - Gut lenght and food habits fish. A note. P. 1-7 (s.n.t.).

LAgleR, K.F.; BARDACH, J.E. \& Müller, R.R.

1962 - Ichthyology: the study of fishes. New York, John Wiley. 545p.

LOWE-MCCONNELL, R.H.

1964 - The fishes of the Rupununi Savanna District of Britsh Guiana, South America. I. Ecological grouping of fish species and effects of the seasonal cycle on the fish. J. Linn. Soc. (Zool.), 45 (304): 103-144.

Magalhães, A.C. DE

1931 - Monographia Brazileira de Peixes Fluviaes. São Paulo, Graphicars. 206p.

MYERS, G.S.

1950 - Studies on South American Freshwater fishes. II. The Genera of Anostominae Characids. Stanf. Ichthyol. Bull., 3 (4): 184-199.

NiKolskI, G.V.

1963 - The ecology of Fishes. London and New York, Academic Press. 352p.

NOMURA, H.

1975 - Marcação e migração de piava, Leporinus copelandi Steindacner, 1875 (Osteichthyes. Anostomidae) do Rio Mogi Guaçu, SP. Ce res, 22 (123): 332-340.
PETRERE, JR., M.

1978 - Pesca e esforço de pesca no Estado do Amazonas. II. Locais, aparelhos de captura e estatísticas de desembarque. Acta Amazonica (Suplemento 2), 8 (3).

ROBERTS, T.R.

1972 - Ecology of fishes in the Amazon and Congo Basins. Bull. Mus, Comp. Zool, , 143 (2): $117-147$

1973 - Interrelationships of Ostariophysans, Zool. J. Linn. Soc. 53 (Supl. 1): 373-395.

SANTos, G.M

1979 - Estudo da alimentação, reprodução e aspectos da Sistemática de Schizodon fasciatus Agassiz, 1829, Rhytiodus microlepis Kner, 1859 e R. argenteofuscus Kner, 1859 do lago Janauacá-AM. Brasil (Osteichthyes, Characoidei, Anostomidae). Tese de Mestrado apresentada ao INPA-FUA. 91p.

SANTOS, G.M. \& GéRY, J.

s.d. - Aspectos biológicos e sistemáticos de alguns Anostomidae (Pisces, Characoidei) da Bacia Amazônica. (Em preparação)

SCHULTZ, L.P.

1944 - The fishes of the family Characinidae from Venezuela, with descriptions of seventeen new forms. Proc. Unit. States Nat. Mus., 95 (3181): 1-367.

STORER, T.I. \& USINGER, R.L.

1974 - Zoologia Geral. Cia. Ed. Nac. Săo Paulo. $757 p$.

Veregina, I.A. \& MEdANI, Yu. I.

1968 - Structure of the digestive tract in Distichodus niloticus $(\mathrm{L})$ and Distichodus rostratus (Gunth.) in relation to the nature of food. Frobl. Ichthol., 8: 567-576.

ZARET, T.M.

1977 - Inhibition of cannibalism in Cichla ocellaris and hypothesis of predator mimicry among south american fishes. Evolution. 2 (31): $421-437$.

(Aceito para publicação em $20 / 03 / 80$ ) 